\title{
Milk and Dairy Products Intake Is Related to Cognitive Impairment at Baseline in Predimed Plus Trial
}

Araceli Muñoz-Garach, Isabel Cornejo-Pareja,* Miguel Ángel Martínez-González, Monica Bulló, Dolores Corella, Olga Castañer, Dora Romaguera, Jesús Vioque, Ángel M. Alonso-Gómez, Julia Wärnberg, J. Alfredo Martínez, Luís Serra-Majem, Ramon Estruch, M. Rosa Bernal-López, * José Lapetra, Xavier Pintó, Josep A. Tur, José López-Miranda, Aurora Bueno-Cavanillas, Miguel Delgado-Rodríguez, Pilar Matía-Martín, Lidia Daimiel, Vicente Martín Sánchez, Josep Vidal, Lucia Prieto, Emilio Ros, Fernando Fernández-Aranda, Lucía Camacho-Barcia, Carolina Ortega-Azorin, María Soria, Miquel Fiol, Laura Compañ-Gabucio, Leire Goicolea-Güemez, Jessica Pérez-López, Nuria Goñi, Judith Pérez-Cabrera, E. Sacanella, Jose Carlos Fernández-García, * Leticia Miró-Moriano, M. Gimenez-Gracia, C. Razquin, Indira Paz-Graniel, Patricia Guillem, María Dolors Zomeño, Manuel Moñino, Alejandro Oncina-Canovas, Itziar Salaverria-Lete, Estefanía Toledo, Jordi Salas-Salvadó, Helmut Schröder, Francisco J. Tinahones, and Predimed-Plus Investigators

Scope: To examine the association between milk and dairy products intake and the prevalence of cognitive decline among Spanish individuals at high cardiovascular risk.

Methods and results: Cross-sectional analyses are performed on baseline data from 6744 adults (aged 55-75 years old). Intake of milk and dairy products is estimated using a food frequency questionnaire grouped into quartiles. The risk of developing cognitive impairment is based on the Mini-Mental State Examination (MMSE).

A higher prevalence of cognitive decline was found in subjects who consumed more grams. Patients with worse MMSE score (10-24) consumed a mean of $395.14 \pm 12.21 \mathrm{~g}$, while patients with better MMSE score (27-30) consumed a mean of $341.23 \pm 2.73 \mathrm{~g}(p<0.05)$. Those subjects with the lower milk consumption ( $<220 \mathrm{~g} /$ day) had a higher MMSE score $(28.35 \pm 0.045)$. Higher intake of fermented dairy products was observed in participants with a lower MMSE score (OR 1.340, $p=0.003$ ). A positive correlation was found between the consumption of whole milk and the MMSE score $(r=0.066, p<0.001)$. Conclusions: These findings suggest that greater consumption of milk and dairy products could be associated with greater cognitive decline according to MMSE. Conversely, consumption of whole-fat milk could be linked with less cognitive impairment in the cross-sectional study.

\section{Introduction}

The worldwide prevalence of dementia is increasing and is predicted to affect 81.1 million people by $2040 .^{[1,2]}$

This will place a considerable burden on health care resources, and will substantially impact quality of life in the individuals affected. As the populations of developed countries around the world age, ${ }^{[3]}$ cognitive decline and dementia are emerging as major health problems. Cognitive decline may range from the very minimal decline associated with normal ageing, to mild cognitive impairment (MCI), or very severe dementia, with the latter regarded as the clinical endpoint of cognitive impairment. ${ }^{[4]}$ Recent evidence indicates that nutrition may play an important role in the causation and prevention of age-related cognitive decline and dementia. ${ }^{[5,6]}$

While positive associations have been shown between a number of nutrients and cognitive performance (antioxidants, folate, omega- 3 and omega- 6 fatty acids), ${ }^{[7-9]}$ little attention has been paid The ORCID identification number(s) for the author(s) of this article can be found under https://doi.org/10.1002/mnfr.202000728

${ }^{[+]}$Present address: Endocrinology Department/IBIMA. Virgen de la Victoria University Hospital, Campus de Teatinos s/n, Malaga 29010 , Spain

DOI: 10.1002/mnfr.202000728 to the potential role of milk and dairy foods in modulating neurological and psychological parameters. Consumption of milk and dairy products may reduce the likelihood of cognitive decline either directly or via mediating effects on cardiometabolic health. A growing body of literature describes this association, but the results of different studies are not conclusive. 
A. Muñoz-Garach, I. Cornejo-Pareja, J. C. Fernández-García ${ }^{[+]}$,

F. J. Tinahones,

Department of Endocrinology and Nutrition

Virgen de la Victoria University Hospital

Malaga University. Instituto de Investigación Biomédica de Málaga (IBIMA)

Avda. Teatinos s/n., Málaga 29010, Spain

E-mail: isabel.cornejo.sspa@juntadeandalucia.es; jcfernandez@uma.es

I. Cornejo-Pareja, M. Á. Martínez-González, M. Bulló, D. Corella,

D. Romaguera, Á. M. Alonso-Gómez, J. Wärnberg, J. A. Martínez,

L. Serra-Majem, R. Estruch, M. R. Bernal-López, J. Lapetra, X. Pintó,

J. A. Tur, J. López-Miranda, E. Ros, F. Fernández-Aranda,

L. Camacho-Barcia, C. Ortega-Azorin, M. Fiol, J. Pérez-López,

J. Pérez-Cabrera, E. Sacanella, J. C. Fernández-García ${ }^{[+]}$, L. Miró-Moriano,

M. Gimenez-Gracia, C. Razquin, P. Guillem, M. Moñino, E. Toledo,

I. Salas-Salvadó, F. J. Tinahones

Centro de Investigación Biomédica en Red Fisiopatología de la Obesidad

y la Nutrición (CIBEROBN)

Institute of Health Carlos III

C/ Monforte de Lemos, 5. Madrid 28029, Spain

E-mail: rosa.bernal@ibima.eu

M. Á. Martínez-González, C. Razquin, E. Toledo

Department of Preventive Medicine and Public Health

University of Navarra

IDISNA. C/ Irunlarrea, 1, Pamplona, Navarra 31008, Spain

M. Á. Martínez-González, C. Razquin, E. Toledo

Department of Nutrition

Harvard T.H. Chan School of Public Health. 665 Huntington Avenue

Boston

Massachusetts 02115, USA

M. Bulló, L. Camacho-Barcia, I. Paz-Graniel, J. Salas-Salvadó

Departament de Bioquímica i Biotecnologia

Unitat de Nutrició. Universitat Rovira i Virgili

Campus Sescelades. C/ Marcel.lí Domingo, 1. Reus, Tarragona 43007, Spain

M. Bulló, L. Camacho-Barcia, I. Paz-Graniel, J. Salas-Salvadó

Nutrition Unit. University Hospital of Sant Joan de Reus.

Avinguda del Doctor Josep Laporte, 2 Reus, Tarragona 43204, Spain

M. Bulló, L. Camacho-Barcia, J. Salas-Salvadó

Institut d'Investigació Sanitària Pere Virgili (IISPV).

Carrer Dr. Mallafré Guasch, 4. Reus, Tarragona 43007, Spain

D. Corella, C. Ortega-Azorin, P. Guillem

Department of Preventive Medicine

University of Valencia.

Av. de Blasco Ibáñez, 13. Valencia 46010, Spain

O. Castañer, M. Soria, M. D. Zomeño, H. Schröder

Unit of Cardiovascular Risk and Nutrition

Institut Hospital del Mar de Investigaciones Médicas Municipal

d'Investigació Médica (IMIM).

Carrer del Dr. Aiguader, 88. Barcelona 08003, Spain

D. Romaguera, M. Fiol, M. Moñino

Health Research Institute of the Balearic Islands (IdISBa). Edificio S

Hospital Universitario Son Espases

Carretera de Valldemossa, 79. Palma, Balearic Islands 07120, Spain

J. Vioque, A. Bueno-Cavanillas, M. Delgado-Rodríguez, V. M. Sánchez,

L. Compañ-Gabucio, A. Oncina-Canovas, H. Schröder

CIBER de Epidemiología y Salud Pública (CIBERESP)

Instituto de Salud Carlos III

C/ Monforte de Lemos, 5., Madrid 28029, Spain

J. Vioque, L. Compañ-Gabucio, A. Oncina-Canovas

Miguel Hernandez University

ISABIAL-FISABIO, Avda Pintor Baeza

12 HGUA. Centro de Diagnóstico., Planta $5^{a}$., Alicante 03010, Spain

Á. M. Alonso-Gómez, L. Goicolea-Güemez, I. Salaverria-Lete

Department of Cardiology

Organización Sanitaria Integrada (OSI) ARABA

University Hospital Araba

C/ Jose Atxotegi Kalea, s/n., Araba Vitoria-Gasteiz 01009, Spain

\section{Á. M. Alonso-Gómez}

University of the Basque Country UPV/EHU

C/ Nieves Cano Kalea, 12. Araba Vitoria-Gasteiz 01006, Spain

J. Wärnberg, J. Pérez-López

Department of Nursing

School of Health Sciences

University of Málaga-Institute of Biomedical Research in Malaga (IBIMA)

Calle Severo Ochoa, 63. Málaga 29590, Spain

J. A. Martínez

Department of Nutrition

Food Sciences, and Physiology

Center for Nutrition Research

University of Navarra

C/ Irunlarrea 1., Pamplona, Navarra 31008 , Spain

J. A. Martínez, L. Daimiel

Nutritional Genomics and Epigenomics Group

IMDEA Food, CEI UAM + CSIC

Crta. de, Carr. de Canto Blanco, 8., Madrid 28049, Spain

L. Serra-Majem, J. Pérez-Cabrera

Nutrition Research Group

Research Institute of Biomedical and Health Sciences (IUIBS)

, University of Las Palmas de Gran Canaria

Instituto Universitario de Investigaciones Biomédicas y Sanitarias

(iUIBS)., Paseo Blas Cabrera Felipe "Físico" (s/n)., 35016 - Las Palmas

de Gran Canaria Islas Canarias

Spain

R. Estruch, E. Sacanella

Department of Internal Medicine

Institut d'Investigacions Biomèdiques August Pi Sunyer (IDIBAPS)

Hospital Clinic

University of Barcelona

Carrer del Rosselló, 149., Barcelona 08036, Spain

M. R. Bernal-López

Department of Internal Medicine

Regional University Hospital of Malaga

Instituto de Investigación Biomédica de Malaga (IBIMA)

Plaza del Hospital Civil

s/n., Malaga 29009, Spain

J. Lapetra, L. Miró-Moriano, M. Gimenez-Gracia

Department of Family Medicine

Research Unit, Distrito Sanitario Atención Primaria Sevilla, Edificio Isla Av. de Ramón y Cajal, 9., Sevilla 41005, Spain

X. Pintó

Lipids and Vascular Risk Unit

Internal Medicine, Hospital Universitario de Bellvitge-IDIBELL,

Hospitalet de Llobregat., Universidad de Barcelona, Carrer de la Feixa

Llarga

s/n., 08907 L'Hospitalet de Llobregat, Barcelona, Spain

X. Pintó

Medicine Department. Universidad de Barcelona

Calle Gran Via de les Corts Catalanes, 585., Barcelona 08007, Spain

J. A. Tur

Research Group on Community Nutrition \& Oxidative Stress

University of Balearic Islands

Carretera de Valldemossa, km 7.5., Palma de Mallorca 07122, Spain

J. López-Miranda

Department of Internal Medicine

Maimonides Biomedical Research Institute of Cordoba (IMIBIC)

Reina Sofia University Hospital

University of Cordoba

Av. Menendez Pidal, s/n., Cordoba 14004, Spain

A. Bueno-Cavanillas

Department of Preventive Medicine and Public Health

University of Granada

Av. del Hospicio, 1., Granada 18010, Spain 
The first cross-sectional studies described this possible relationship and found that higher milk and dairy product intake could be likely to have a protective effect against cognitive impairment. ${ }^{[10-12]}$ Later, two cohort studies ${ }^{[13,14]}$ reported contradictory results. Almeida et al. in their cohort of men aged 80 and over, observed the influence of fat in milk; and regular full-cream milk consumption was inversely related to good mental health at follow-up compared with rare consumption. ${ }^{[13]}$ The study by Vercambre et al. found no significant associations between milk and dairy product consumption and cognitive decline in French elderly women. ${ }^{[14]}$

Subsequently, the meta-analysis by $\mathrm{Wu}$ et al. supported the idea that high milk consumption was associated with a lower likelihood of cognitive impairment in Asian populations. However, high intakes of full-fat milk and dairy products may be associated with decline in cognitive performance. ${ }^{[15]}$ These concepts were not validated in two contemporary prospective cohort studies among older male and female adults after a long-term follow-up. Kesse-Guyot et al. observed that milk intake was negatively associated with verbal memory performance, ${ }^{[16]}$ and Petruski-Ivleva

\section{Delgado-Rodríguez}

Division of Preventive Medicine

Faculty of Medicine

University of Jaén

Campus Las Lagunillas, s/n., Jaén 23071, Spain

P. Matía-Martín

Department of Endocrinology and Nutrition

Instituto de Investigación Sanitaria Hospital Clínico San Carlos (IdISSC)

Calle del Prof Martín Lagos, s/n., Madrid 28040, Spain

V. M. Sánchez

Institute of Biomedicine (IBIOMED)

University of León

Campus Universitario de Vegazana s/n., León 24071, Spain

J. Vidal

CIBER Diabetes y Enfermedades Metabólicas (CIBERDEM)

Instituto de Salud Carlos III (ISCIII)

C/ Monforte de Lemos, 5., Madrid 28029, Spain

J. Vidal

Department of Endocrinology

Institut d'Investigacions Biomédiques August Pi Sunyer (IDIBAPS)

Hospital Clinic, University of Barcelona

Carrer del Rosselló, 149., Barcelona 08036, Spain

L. Prieto

Department of Endocrinology

Fundación Jiménez-Díaz

Av. de los Reyes Católicos, 2., Madrid 28040, Spain

E. Ros

Lipid Clinic

Department of Endocrinology and Nutrition

Institut d'Investigacions Biomèdiques August Pi Sunyer (IDIBAPS)

Hospital Clínic

Carrer del Rosselló, 149., Barcelona 08036, Spain

F. Fernández-Aranda

Department of Psychiatry

University Hospital of Bellvitge-IDIBELL and Department of Clinical

Sciences

School of Medicine and Health Sciences., University of Barcelona

Campus de Bellvitge, Feixa Llarga, s/n., 08907 L'Hospitalet de Llobregat

Barcelona, Spain

N. Goñi

Navarro Health Service., Primary Care Pamplona

Plaza de la Paz s/n., Navarra 31002 , Spain et al. found that milk intake greater than one glass per day during midlife was associated with a higher rate of cognitive decline over a 20-year period. ${ }^{[17]}$ Previous epidemiological and clinical studies have concluded that fermented dairy products can help to prevent cognitive decline. ${ }^{[18,19]}$ A systematic review in 2017 compiled information from 7 cohort studies and one randomized controlled trial. This review revealed that the current evidence was inadequate to draw a conclusion for the causal relationship between milk or dairy intake and cognitive decline or disorders in older adults as the majority of studies were observational. ${ }^{[20]}$

On the other hand, type 2 diabetes (T2D) and obesity are well recognized risk factors for poor cognitive outcomes, including cognitive decline, $\mathrm{MCI}$, and dementia. ${ }^{[21,22]}$ It has been estimated that 175000 Alzheimer's disease cases in the United States could be attributable to T2D. ${ }^{[23]}$ Approximately one-quarter of older adults are diabetic, and an additional 50\% are prediabetic. Given the high prevalence of T2D and obesity, it is becoming increasingly important to better understand the association between T2D and cognitive outcomes. These medical conditions are risk factors for cardiovascular disease and are suggested to also increase the likelihood of reduced cognitive function in later life. Observational, epidemiological and intervention trials indicate that milk and dairy consumption may have positive effects on metabolic parameters. ${ }^{[24-28]}$ If milk and dairy product consumption can improve cardiometabolic health, a beneficial consequence of this may contribute to reducing the risk of cognitive decline. Recent reviews, however, have suggested that milk and dairy product intake, although associated with better cardiometabolic health, may also be associated with cognitive impairment. ${ }^{[17]}$ Given the mixed results and the potential global impact that milk and dairy product consumption may have on cognitive decline and cardiovascular diseases outcomes, understanding these relationships is crucial for informing dietary guidelines. Therefore, the objective of this study was to examine the relationship between milk and dairy product intake and the prevalence of cognitive impairment and cognitive test performance among Spanish individuals at high cardiovascular risk.

\section{Experimental Section}

The cross-sectional associations between baseline milk and dairy product consumption and cognitive outcomes among patients enrolled in PREDIMED-PLUS study were investigated. Patient consumption from the lowest to highest quantities of milk and dairy products was compared. Thus, 6744 Spanish women and men who were free from cardiovascular disease and cancer and who completed a 146-item food frequency questionnaire (FFQ; presenting data on milk and dairy product consumption) between the years 2013 and 2016 were reviewed. The cases of cognitive disorders were recorded after assessing the MiniMental State Examination (MMSE) as a cognitive function test. Scores from the Beck Depression Inventory (BDI-II) were also evaluated.

\subsection{Study Design and Participants}

The present study is a cross-sectional analysis of baseline data within the framework of the PREDIMED-PLUS study, a 6-year 
6874 possible participants (in 23 Spanish centres) between the years 2013 to 2016

130 participants did not completed a 146 -item food frequency questionnaire with

data on milk and dairy product consumption and were excluded

6744 participants were evaluated by their data on milk and dairy product consumption

318 patients more that did not completed MMSE questionnaire or those patients

with a score of 10 or less were excluded from the analysis.

6426 participants included (those who have completed the MMSE questionnaire validated for the Spanish

population and food frequency questionnaire).

The diagram shows the selection patients process for our study.

Figure 1. Flow chart diagram of the selection patients in our analysis.

multicenter, randomized, parallel-group, primary prevention clinical trial conducted in Spain to assess the effect on cardiovascular disease morbidity and mortality of an intensive weight-loss intervention program based on an energy-restricted traditional Mediterranean diet with promotion of physical activity and behavioral support compared to a usual care intervention with an energy-unrestricted Mediterranean diet only (control group) and no goals for weight loss. A more detailed description of the PREDIMED-PLUS study is available at http://predimedplus. com/29] (Data Base: 201706131354_PREDIMEDplus_201706-13). This study was registered at the International Standard Randomized Controlled Trial (ISRCT; http://www.isrctn. com/ISRCTN89898870) with the registration number 89898870. Registration date: 24 July 2014.

From September 2013 to December 2016, a total of 6874 participants were recruited and randomized in 23 centers from different universities, hospitals and research institutes in Spain. 130 participants did not complete a 146-item FFQ with data on milk and dairy products consumption and were excluded. 6744 participants were evaluated by their data on milk and dairy products consumption but 318 patients did not complete MMSE questionnaire or presented a score of 10 or less, so they were excluded from the analysis. Finally, 6426 participants were included (those who have completed the MMSE questionnaire validated for the Spanish population and the FFQ (Figure 1).

Each of these centers recruited participants from several primary health care facilities pertaining to the National Health System. The eligible participants were community-dwelling adults (men aged 55-75; women aged 60-75 (48.5\%)), who were overweight or obese (body mass index [BMI] $<40 \mathrm{~kg} \mathrm{~m}^{-2}$ ), met at least three criteria for the metabolic syndrome according to the updated harmonized criteria of the International Diabetes Feder- ation, the American Heart Association, and the National Heart, Lung and Blood Institute, ${ }^{[30]}$ and were without cardiovascular disease at enrolment.

All participants provided written informed consent, and the study protocol and procedures were approved according to the ethical standards of the Declaration of Helsinki by all the research ethics committees (RECs) or clinical research ethics committees (CRECs) of the participating institutions: REC Malaga, REC Virgen Macarena and Virgen del Rocío University Hospitals, REC University of Navarra, REC Balearic Islands, CREC Clinical Hospital of Barcelona, CREC Barcelona MAR Health Park, CREC Sant Joan de Reus University Hospital, REC San Cecilio University Hospital, CREC Jiménez Díaz Foundation, CREC Basque Country, REC University of Valencia, CREC Doctor Negrón University Hospital of Gran Canaria, CREC Bellvitge University Hospital, REC Córdoba, REC Madrid Institute for Advanced Studies, CREC San Carlos Clinical Hospital, REC for Biomedical Research of Andalusia, and CREC León.

At the first visit, the examination by the physician or dietitiannutritionist included a review of the medical history and administration of the MMSE. For analysis, all participants who completed the MMSE questionnaire validated for the Spanish population were included. ${ }^{[31]}$ A 146-item FFQ was performed. In total, information on 6426 participants who completed both questionnaires was included.

\subsection{Dietary Assessment}

Intake of milk and dairy foods was assessed using a selfadministered FFQ on which participants reported their average frequency and quantity consumed (in grams) of 146 food and beverage items during the previous week. This FFQ requests 
information relating to food choices, preparation, portion size, quantity and consumption of milk and dairy products, and of different food and beverage items.

Total daily milk intake from all sources was calculated, and the fat content of each item categorized into whole fat, semiskimmed and skimmed from the FFQ. Milk and dairy intakes were categorized into quartiles. Detailed information on fermented dairy products (all types of cheese, cottage cheese and yoghurt but no dairy desserts) was analyzed.

\subsection{Assessment of Cognitive Functioning}

Currently, the MMSE is the most commonly used brief cognitive screening test. The MMSE measures five cognitive domains: serial subtraction, language, memory, orientation, and visuospatial. It is a 30-point questionnaire which examines functions including registration (repeating named prompts), attention and calculation, recall, language, ability to follow simple commands, and orientation). The MMSE is scored from 0 to 30, with higher scores indicating absence of cognitive decline. It was developed in 1975 as a global assessment of cognitive status. A perfect score is 30 points; those patients with a score of 10 or less were excluded from the analysis. An MMSE score between 10 and 24 was considered mild to moderate dementia, a score between 25 and 26 was considered uncertain/questionable dementia and an MMSE score between 27 and 30 was considered a normal cognitive range.

Individuals who performed in the normal cognitive range and did not meet criteria for MCI or dementia, which was diagnosed using DSM-IV criteria, ${ }^{[32]}$ were deemed clinically unimpaired. The ease of administering the MMSE and its utility in detecting Alzheimer's disease has made it a popular neuropsychological tool. ${ }^{[33]}$

Assessment of depressive symptoms was undertaken using the BDI-II in addition to cognitive state. A total score ranging from 0 to 63 was calculated, with higher scores indicating more frequent depressive mood. Suggested score ranges for mild depression, moderate to severe depression and severe depression were 10-19, 20-30, and 31 or higher, respectively. ${ }^{[34]}$

\subsection{Covariate Assessment}

The covariates were evaluated using self-reported general questionnaires about socio-demographic factors (gender, age, educational level, and employment status), smoking habits, personal history of illness, medical conditions, and medication use. These were collected prior to randomization. Anthropometric variables and blood pressure were determined by trained staff and in accordance with the PREDIMED-PLUS operations protocol. Obesity was defined as a BMI $\geq 30 \mathrm{~kg} \mathrm{~m}^{-2}$. T2D was defined as having a previous clinical diagnosis of diabetes, or HbA1c levels $\geq 6.5 \%$ or use of antidiabetic medication at baseline. Individual components of the metabolic syndrome were defined as follows: abdominal obesity (waist circumference $\geq 102 \mathrm{~cm}$ in men; $\geq 88 \mathrm{~cm}$ in women), high blood pressure (systolic and/or diastolic $\geq 130 / 85 \mathrm{mmHg}$ or using antihypertensive drugs), hyperglycemia (glucose $\geq 100 \mathrm{mg} \mathrm{dL}^{-1}$ or taking medication for elevated glucose), hypertriglyceridemia (triglycerides $\geq 150 \mathrm{mg} \mathrm{dL}^{-1}$ or taking triglyceride-lowering medication), low HDL-cholesterol (HDL-c $<40 \mathrm{mg} \mathrm{dL}^{-1}$ in men and $<50 \mathrm{mg} \mathrm{dL}^{-1}$ in women or taking HDL-c raising medication). Physical activity was self-reported by the Minnesota test.

\subsection{Statistical Analysis}

Statistical analyses of the data were performed primarily using the SPSS program (version 22.0.0 for Windows, SPSS Iberica, Spain). Statistical significance was set at $p<0.05$. Baseline characteristics were described as means and dispersion (standard deviation, SD) for quantitative variables and as proportions for qualitative variables. Baseline consumption of milk and dairy products was categorized into approximate quartiles, defining the four groups as "Very low" Q1 (<220 g/day), "Low" Q2 (221307 g/day), "Low to Moderate" Q3 (308-499 g/day) and "Moderate to High" Q4 ( $\geq 500 \mathrm{~g} /$ day). The total scores on the MMSE across the four levels of milk and dairy product consumption were compared.

The differences according to MMSE score were also analyzed. Subjects were divided according to MMSE score in three groups to differentiate those with mild to moderate risk of dementia (MMSE score 10-24) from those with uncertain/questionable risk of dementia (MMSE score 25-26) and no dementia risk (MMSE score $\geq 27$ ). Quartiles of milk and dairy intake with ANOVA were compared. The relationship was analyzed using Pearson correlations models and linear regression models. Four different models were used to study the link between milk and dairy products consumption and dementia, measured with the score provided by the MMSE questionnaire. In the first model, the global mean intake of milk and dairy products was analyzed; in the second, fermented dairy product intake was analyzed; in the third model, whole-fat milk and dairy products consumption was analyzed and in the fourth model, skimmed milk and dairy products consumption were analyzed.

Binary logistic regression models were fitted to assess the relationship between dementia (by MMSE score) and milk and dairy product intake based on consumption of $100 \mathrm{~g}$ and categorized by quartiles. Odds ratios and their 95\% confidence intervals were calculated considering the lowest quartile as the reference category. To control for potential confounding factors, the results were adjusted for ten covariates that were known as potential risk or protective factors for cognitive decline and : age (years, continuous); gender (male or female); BMI $\left(\mathrm{kg} \mathrm{m}^{-2}\right)$; smoking habits (non-smoker, former smoker, smoker); educational level (years of school, continuous); history of diabetes mellitus; history of high blood pressure, depression diagnosis, BDI-II score (absence-mild depression risk [score 0-19] or moderate-severe depression risk [score 20-63]), physical activity (measured by total caloric expenditure); and nutritional information adjusted by food groups (consumption of meat, fish, vegetables, fruits, dried fruits, alcohol). Three adjusted models were constructed: Model 1: adjusted for gender, age and BMI. Model 2: adjusted for gender, age, BMI, smoking habit, years of school. Model 3: adjusted for gender, age, BMI, smoking habit, years of school, diagnosis of T2D, diagnosis of high blood pressure, diagnosis of depression, and moderate-high risk of depression assessed by the BDI-II. Model 4: adjusted for gender, age, BMI, smoking 
habit, years of school, diagnosis of T2D, diagnosis of high blood pressure, diagnosis of depression, and moderate-high risk of depression assessed by the BDI-II, physical activity (measured by total caloric expenditure). Model 5: adjusted for gender, age, BMI, smoking habit, years of school, diagnosis of T2D, diagnosis of high blood pressure, diagnosis of depression, and moderatehigh risk of depression assessed by the BDI-II, physical activity, food groups (consumption of meat, fish, vegetables, fruits, dried fruits, alcohol). Model 6: adjusted for gender, age, BMI, smoking habit, years of school, diagnosis of T2D, diagnosis of high blood pressure, diagnosis of depression, and moderate-high risk of depression assessed by the BDI-II, physical activity, food groups (consumption of meat, fish, vegetables, fruits, dried fruits, alcohol), consumption of exciting foods such as coffee, tea, and cocoa.

\section{Results}

The mean age of the participants was $65 \pm 4.9$ years, $48.5 \%$ of whom were women. Of the total, $27.2 \%$ of the patients were diabetic, $69.3 \%$ had dyslipidemia, $83.1 \%$ had high blood pressure, and $12.5 \%$ were smokers. Concerning the level of education attained, $47.7 \%$ had primary school studies or less, $28.9 \%$ had secondary studies and $22.1 \%$ were college graduates. Retirees accounted for $55.9 \%$, and $20.8 \%$ were active workers. Prior to inclusion, $20.8 \%$ had a diagnosis of depression; $91 \%$ had a BDI-II score under 20 , and $9 \%$ had a moderate to severe risk of depression (score 20-30). Regular physical activity was undertaken by $43.3 \%$ of the patients, while $52.6 \%$ had sedentary behaviour.

We calculated the percentage of patients according to their MMSE score to assess the degree of dementia: $5 \%$ scored between 10 and 24, 9\% between 25 and 26, and 79.5\% had no dementia (MMSE score 27-30). The baseline characteristics of the PREDIMED-Plus participants are shown in Table 1 according to quartiles of milk and dairy product intake. Those patients with a lower intake of milk and dairy products ( $<220 \mathrm{~g} /$ day: Q1) had a mean MMSE of $28.4 \pm 1.8$ while subjects consuming more than $\geq 500 \mathrm{~g} /$ day (Q4) of milk and dairy products had a mean MMSE score of $28.0 \pm 2.1 p<0.001$. Participants included in Q2 and Q3 had an MMSE score of $28.2 \pm 1$.9. Supplementary Table 1 shows additional information regarding the fat content of the milk and dairy products, intake of fermented products and MMSE score according to quartiles of milk and dairy product consumption.

We studied the relationship between analytical parameters and the MMSE score; higher glucose levels were presented in those subjects with a lower MMSE score $(r=-0.042, p=0.001)$. When we analyzed lipid profiles, a higher MMSE score was observed in subjects with higher triglycerides, total cholesterol and LDL cholesterol values $(r=0.039, p=0.002 ; r=0.025, p=0.049$; $r=0.026, p=0.044$, respectively). Unexpectedly, HDL cholesterol showed an inverse relationship $(r=-0.055, p<0.001)$ with the MMSE score.

The relationship between overall milk and dairy product consumption and cognitive decline evaluated by the MMSE was analyzed (Table 2). We found higher total milk and dairy product intake in subjects with lower MMSE scores. Those subjects who consumed more fermented dairy products had a lower MMSE score. Conversely, those who consumed a higher quantity of whole-fat milk and dairy products had a higher MMSE score. No statistically significant differences were found in the percentage of semi-skimmed and skimmed milk and dairy products between groups according to MMSE score (Table 2).

Total milk and dairy product intake showed a negative correlation with the MMSE score $(r=-0.07, p<0.001)$. We analyzed our results dividing the participants according to the type of dairy products consumed. Correlation was found in the same way; fermented $(r=-0.027, p=0.032)$ versus non-fermented $(r=-0.067$, $p<0.001)$.

We divided subjects according to the fat content of the milk and dairy products. Intake of semi-skimmed and skimmed milk was higher in those participants with lower MMSE score $(r=-0.031$, $p=0.013$ and $r=-0.027, p=0.033$, respectively), whereas intake of whole milk was more frequent in those subject with a higher MMSE score $(r=0.066, p<0.001)$. Therefore, it may be postulated the fat provided by milk and dairy products could be related with higher cognitive function.

When we evaluated the possible implication of the overall consumption of milk and dairy products in the diet, we found that this was associated with a $10.5 \%$ increase in the odds of presenting dementia in the crude model (OR 1.105 [1.071-1.141], $p<0.001)$. This trend was also maintained in the adjusted models by the confounding variables (Table 3). Likewise, the consumption of fermented dairy products was also associated with an increase of $12.1 \%$ in the odds of presenting dementia in the crude model (OR 1.121 [1.042-1.205], $p=0.002$ ), with this relationship being maintained in the adjusted models (Table 3 ). However, we found that whole-fat milk did not influence cognitive decline in either the crude model (OR 0.966 [0.935-1.062], $p=0.913$ ) or the adjusted models (Table 3 ).

Multiple logistic regression analysis of the quartiles of total milk and dairy consumption revealed an increase in the odds of cognitive decline (evaluated by abnormal MMSE scores $\leq 26$ ) in those patients with a higher intake ( $\geq 500 \mathrm{~g} /$ day: Q4) in the crude model (OR 1.612 [1.326-1.959], $p<0.001$ ), as well as in the models adjusted for the confounding variables (Table 4), versus subjects whose overall milk and dairy product intake was lower than $<220$ g/day: Q1 (Table 4).

We also performed a multiple logistic regression analysis of the quartiles of fermented dairy product consumption which showed that a higher consumption of fermented dairy products (Q4) was related to an increase of $34 \%$ in the odds of worse cognitive function in the crude model (OR 1.340 [1.106-1.625], $p=$ $0.003)$. However, this possible association was not significant in the adjusted models (Table 5).

Multiple logistic regression analysis were also calculated dividing our population into quartiles according to their consumption of whole milk and dairy products (Table 6). A higher proportion of whole-fat milk and dairy products consumed ( $\geq 103 \mathrm{~g} /$ day: Q4) was significantly associated with a $24.9 \%$ decrease in the odds of cognitive impairment according to the MMSE in the crude model (OR 0.751 [0.623-0.906], $p=0.003$ ), compared to subjects with a lower whole-fat milk and dairy product intake $(\leq 18 \mathrm{~g} /$ day: Q1). However, this association was not significant in the adjusted models (Table 6). The moderate consumption of wholefat milk and dairy (Q2 and Q3) gave higher protection against cognitive decline according to our results, which were $31.1 \%$ and 
Table 1. Baseline characteristics of the participants from the PREDIMED-PLUS trial according to Quartiles of Milk and Dairy product intake.

\begin{tabular}{|c|c|c|c|c|c|c|c|c|c|}
\hline \multirow[t]{3}{*}{ Variables } & \multirow{2}{*}{\multicolumn{2}{|c|}{$\begin{array}{l}\text { Milk and dairy product } \\
\text { intake }<220 \text { g/day (Q } 1) \\
(n=1669)\end{array}$}} & \multirow{2}{*}{\multicolumn{2}{|c|}{$\begin{array}{c}\text { Milk and dairy product } \\
\text { intake } 221-307 \mathrm{~g} / \text { day } \\
(\mathrm{Q} 2)\end{array}$}} & \multirow{2}{*}{\multicolumn{2}{|c|}{$\begin{array}{c}\begin{array}{c}\text { Milk and dairy product } \\
\text { intake 308-499 g/day } \\
\text { (Q3) }\end{array} \\
(n=1688)\end{array}$}} & \multirow{2}{*}{\multicolumn{2}{|c|}{$\begin{array}{c}\begin{array}{c}\text { Milk and dairy product } \\
\text { intake } \geq 500 \mathrm{~g} / \text { day } \\
(\mathrm{Q} 4)\end{array} \\
(n=1699)\end{array}$}} & \multirow[t]{3}{*}{$p$} \\
\hline & & & & & & & & & \\
\hline & MEAN & SD & MEAN & SD & MEAN & SD & MEAN & SD & \\
\hline Age [years] & 64.6 & 5.0 & 64.7 & 4.9 & 65.1 & 4.9 & 65.4 & 4.9 & $<0.001$ \\
\hline Female gender [\%] & 40.9 & & 44.5 & & 51.3 & & 57.0 & & $<0.001$ \\
\hline Weight [kg] & 87.7 & 13.0 & 86.7 & 12.9 & 86.4 & 13.0 & 85.7 & 12.8 & $<0.001$ \\
\hline Waist circumference $[\mathrm{cm}]$ & 108.2 & 9.7 & 107.7 & 9.6 & 107.2 & 9.7 & 107.2 & 9.7 & 0.010 \\
\hline Hip circumference $[\mathrm{cm}]$ & 109.7 & 8.1 & 109.6 & 8.3 & 110.1 & 8.8 & 110.7 & 8.7 & 0.001 \\
\hline BMI $\left[\mathrm{kg} \mathrm{m}^{-2}\right.$ ) & 32.6 & 3.4 & 32.5 & 3.4 & 32.6 & 3.5 & 32.6 & 3.5 & 0.839 \\
\hline Educational level [years] & 11.8 & 5.6 & 11.2 & 5.2 & 11.3 & 5.3 & 11.0 & 5.4 & $<0.001$ \\
\hline Smokers [\%] & 14.6 & & 13.7 & & 10.9 & & 10.6 & & $<0.001$ \\
\hline Former Smokers [\%] & 48.0 & & 44.3 & & 43.6 & & 38.3 & & $<0.001$ \\
\hline Time smoking [years] & 37.1 & 12.9 & 36.6 & 12.8 & 37.4 & 11.7 & 38.2 & 12.4 & 0.643 \\
\hline Cigarette smoking [pack-years] & 23.9 & 20.1 & 25.1 & 21.2 & 19.3 & 18.8 & 26.1 & 21.8 & 0.016 \\
\hline Total energy intake [kcal/day] & 2227.9 & 572.0 & 2336.1 & 585.3 & 2461.3 & 607.1 & 2606.4 & 680.3 & $<0.001$ \\
\hline Vegetables [g/day] & 316.9 & 135.0 & 316.5 & 139.6 & 332.6 & 136.1 & 338.9 & 147.1 & $<0.001$ \\
\hline Fruits [g/day] & 333.2 & 210.8 & 349.7 & 205.8 & 366.4 & 197.3 & 387.6 & 219.6 & $<0.001$ \\
\hline Legumes [g/day] & 19.9 & 11.3 & 20.1 & 10.2 & 21.2 & 11.4 & 21.6 & 11.7 & $<0.001$ \\
\hline Grains [g/day] & 146.3 & 83.7 & 151.9 & 81.0 & 151.0 & 80.2 & 164.6 & 87.1 & $<0.001$ \\
\hline Meats and subproducts [g/day] & 142.8 & 60.9 & 148.7 & 58.3 & 151.2 & 58.0 & 148.6 & 63.7 & 0.001 \\
\hline Fish [g/day] & 99.3 & 47.0 & 99.2 & 46.0 & 106.1 & 47.2 & 101.4 & 49.3 & $<0.001$ \\
\hline Dried fruits [g/day] & 15.2 & 18.2 & 14.2 & 16.8 & 16.1 & 18.7 & 15.5 & 18.1 & 0.017 \\
\hline Olive oil [g/day] & 41.0 & 17.4 & 40.6 & 17.0 & 40.1 & 16.7 & 39.1 & 17.5 & 0.009 \\
\hline Alcohol [g pure alcohol] & 13.7 & 17.5 & 12.5 & 16.7 & 10.6 & 13.8 & 7.9 & 12.0 & $<0.001$ \\
\hline Vitamin D [mcg/day] & 5.9 & 3.4 & 6.0 & 3.3 & 6.5 & 3.5 & 6.2 & 3.5 & $<0.001$ \\
\hline Calcium [mg/day] & 712.2 & 202.8 & 913.0 & 184.9 & 1101.2 & 246.6 & 1446.0 & 321.0 & 0.891 \\
\hline Carbohydrates [\%] & 39.5 & 7.3 & 40.4 & 6.7 & 40.6 & 6.5 & 43.2 & 6.3 & $<0.001$ \\
\hline Proteins [\%] & 15.7 & 2.8 & 16.3 & 2.6 & 16.8 & 2.6 & 17.3 & 2.8 & $<0.001$ \\
\hline Total fat [\%] & 40.7 & 7.0 & 39.9 & 6.5 & 39.7 & 6.1 & 37.5 & 6.2 & $<0.001$ \\
\hline MMSE score & 28.4 & 1.8 & 28.2 & 1.9 & 28.2 & 1.9 & 28.0 & 2.1 & $<0.001$ \\
\hline Glucose $\left[\mathrm{mg} \mathrm{dL}^{-1}\right]$ & 113.4 & 28.7 & 113.4 & 27.6 & 111.4 & 27.6 & 115.3 & 32.2 & 0.002 \\
\hline Triglycerides [mg dL ${ }^{-1}$ ] & 157.7 & 87.6 & 153.1 & 78.4 & 148.7 & 74.6 & 150.3 & 75.0 & 0.006 \\
\hline Total cholesterol $\left[\mathrm{mg} \mathrm{dL}^{-1}\right]$ & 197.9 & 38.7 & 196.4 & 37.5 & 197.6 & 37.9 & 196.8 & 37.1 & 0.644 \\
\hline HbAlc [\%] & 6.08 & 0.9 & 6.09 & 0.8 & 6.06 & 0.8 & 6.22 & 1.0 & $<0.001$ \\
\hline
\end{tabular}

Data are presented as mean \pm SD unless otherwise indicated. BMI, body mass index; HDL-c, high-density lipoprotein cholesterol; MMSE, Mini-Mental State Examination; SD, standard deviation.

Table 2. Milk and dairy product consumption according to MMSE score.

\begin{tabular}{|c|c|c|c|c|c|c|c|}
\hline \multirow[t]{2}{*}{ Variables } & \multicolumn{2}{|c|}{ MMSE $10-24 n=343$} & \multicolumn{2}{|c|}{ MMSE $25-26 n=616$} & \multicolumn{2}{|c|}{ MMSE $27-30 n=5467$} & \multirow[t]{2}{*}{$P$} \\
\hline & MEAN & SD & MEAN & SD & MEAN & SD & \\
\hline MMSE score & 22.5 & 1.8 & 25.6 & 0.5 & 28.8 & 1.0 & $<0.001$ \\
\hline Total milk and dairy products [g] & 395.1 & 225.4 & 380.5 & 215.4 & 341.2 & 201.0 & $<0.001$ \\
\hline Fermented dairy products [g] & 123.0 & 102.6 & 114.5 & 91.3 & 107.7 & 88.4 & 0.003 \\
\hline Non-fermented dairy products [g] & 272.2 & 190.9 & 266.0 & 188.4 & 233.4 & 176.4 & $<0.001$ \\
\hline Whole-milk and dairy products [\%] & 23.8 & 29.5 & 25.0 & 29.2 & 29.7 & 31.4 & $<0.001$ \\
\hline Semi-skimmed milk and dairy products [\%] & 33.0 & 34.6 & 31.4 & 34.3 & 30.0 & 33.7 & 0.189 \\
\hline Skimmed milk and dairy products [\%] & 43.3 & 37.6 & 43.6 & 38.1 & 40.3 & 37.9 & 0.060 \\
\hline
\end{tabular}

MMSE, Mini-Mental State Examination; SD, standard deviation. 
Table 3. Adjusted models for cognitive decline screening (abnormal MMSE test).

Cognitive decline screening (MMSE)

\begin{tabular}{|c|c|c|c|c|c|c|c|c|}
\hline & \multicolumn{2}{|c|}{$\begin{array}{l}\text { Milk and dairy products global } \\
\text { consumption } / 100 \mathrm{~g}\end{array}$} & \multicolumn{2}{|c|}{ Fermented dairy products/100 g } & \multicolumn{2}{|c|}{$\begin{array}{l}\text { Whole fat milk and dairy } \\
\text { products } / 100 \mathrm{~g}\end{array}$} & \multicolumn{2}{|c|}{$\begin{array}{l}\text { Skimmed milk and dairy } \\
\text { products } / 100 \mathrm{~g}\end{array}$} \\
\hline & OR $(\mathrm{Cl})$ & $p$ & OR $(\mathrm{Cl})$ & $p$ & OR $(\mathrm{Cl})$ & $p$ & OR $(\mathrm{Cl})$ & $p$ \\
\hline Crude model & $1.105(1.071-1.141)$ & $<0.001$ & $1121(1.042-1.205)$ & 0.002 & $0.966(0.935-1.062)$ & 0.913 & $1.244(1.038-1.491)$ & 0.018 \\
\hline Model 1 & $1.086(1.051-1.123)$ & $<0.001$ & 1.085 (1.006-1.171) & 0.034 & $1.052(0.987-1.120)$ & 0.118 & $1.078(0.894-1.299)$ & 0.432 \\
\hline Model 2 & $1.083(1.045-1.122)$ & $<0.001$ & $1.104(1.018-1.198)$ & 0.017 & $1.035(0.968-1.107)$ & 0.311 & $1.175(0.963-1.433)$ & 0.113 \\
\hline Model 3 & $1.083(1.045-1.123)$ & $<0.001$ & $1.105(1.017-1.201)$ & 0.018 & $1.040(0.971-1.114)$ & 0.258 & $1.164(0.950-1.427)$ & 0.142 \\
\hline Model 4 & $1.084(1.045-1.124)$ & $<0.001$ & $1.100(1.012-1.196)$ & 0.025 & $1.043(0.974-1.117)$ & 0.224 & $1.154(0.942-1.414)$ & 0.154 \\
\hline Model 5 & $1.082(1.043-1.123)$ & $<0.001$ & $1.097(1.008-1.193)$ & 0.032 & $1.045(0.976-1.119)$ & 0.210 & $1.141(0.930-1.400)$ & 0.208 \\
\hline Model 6 & $1.084(1.045-1.125)$ & $<0.001$ & 1.099 (1.010-1.197) & 0.028 & $1.048(0.978-1.123)$ & 0.181 & $1.139(0.928-1.298)$ & 0.214 \\
\hline
\end{tabular}

Binary logistic regression analysis: Odds ratio (OR) and $95 \%$ confidence interval $(\mathrm{CI})$ for the association between cognitive impairment associated with overall consumption $100 \mathrm{~g}$ of milk and dairy products, fermented dairy products, whole-fat milk and dairy products and skimmed milk and dairy products in the PREDIMED-PLUS trial. An abnormal MMSE questionnaire was defined as a score $\leq 26$ points. Dependent variable: cognitive decline screening-MMSE score between 27 and 30 points ( 0$)$ versus MMSE score $\leq 26$ points (1). Model 1: adjusted for gender, age and BMI. Model 2: additionally adjusted for smoking habit, years of school. Model 3: additionally adjusted for diagnosis of T2D, diagnosis of high blood pressure, diagnosis of depression and moderate to high risk of depression assessed by the BDI-II. Model 4: additionally adjusted for physical activity (measured by total caloric expenditure). Model 5: additionally adjusted for food groups (consumption of meat, fish, vegetables, fruits, dried fruits, alcohol). Model 6: additionally adjusted for exciting foods (coffee, tea, and cocoa). MMSE, Mini-Mental State Examination; OR, odds ratio; Cl: confidence interval.

Table 4. Adjusted models for cognitive decline screening (abnormal MMSE test)—Milk and dairy product intake in quartiles.

\begin{tabular}{|c|c|c|c|c|c|c|c|}
\hline & \multicolumn{7}{|c|}{ Cognitive decline screening (MMSE) } \\
\hline & \multirow{3}{*}{$\begin{array}{c}\text { Q1 } \\
\text { Milk and } \\
\text { dairy intake } \\
<220 \mathrm{~g} / \text { day }\end{array}$} & \multicolumn{2}{|l|}{ Q2 } & \multicolumn{2}{|l|}{ Q3 } & \multicolumn{2}{|c|}{ Q4 } \\
\hline & & \multicolumn{2}{|c|}{ Milk and dairy intake $221-307 \mathrm{~g} /$ day } & \multicolumn{2}{|c|}{ Milk and dairy intake $308-499 \mathrm{~g} /$ day } & \multicolumn{2}{|c|}{ Milk and dairy intake $\geq 500 \mathrm{~g} /$ day } \\
\hline & & $\mathrm{OR}(\mathrm{Cl})$ & $p$ & $\mathrm{OR}(\mathrm{Cl})$ & $p$ & $\mathrm{OR}(\mathrm{Cl})$ & $p$ \\
\hline Crude model & 1.0 (ref) & $1.119(0.911-1.376)$ & 0.285 & $1.216(0.992-1.490)$ & 0.059 & $1.612(1.326-1.959)$ & $<0.001$ \\
\hline Model 1 & 1.0 (ref) & $1.099(0.891-1.356)$ & 0.379 & $1106(0.899-1.361)$ & 0.342 & $1.399(1.145-1.709)$ & 0.001 \\
\hline Model 2 & 1.0 (ref) & $0.983(0.788-1.228)$ & 0.882 & $1.083(0.870-1.348)$ & 0.476 & $1.286(1.039-1.591)$ & 0.021 \\
\hline Model 3 & 1.0 (ref) & $1.001(0.799-1.255)$ & 0.992 & $1.112(0.889-1.391)$ & 0.351 & $1.298(1.044-1.613)$ & 0.019 \\
\hline Model 4 & 1.0 (ref) & $1.001(0.799-1.255)$ & 0.993 & $1.099(0.878-1.374)$ & 0.410 & $1.302(1.047-1.619)$ & 0.018 \\
\hline Model 5 & 1.0 (ref) & $1.003(0.800-1.258)$ & 0.980 & $1.095(0.875-1.371)$ & 0.429 & $1.291(1.037-1.608)$ & 0.022 \\
\hline Model 6 & 1.0 (ref) & $1.002(0.799-1.257)$ & 0.984 & $1.102(0.880-1.380)$ & 0.396 & $1.302(1.045-1.622)$ & 0.019 \\
\hline
\end{tabular}

Binary logistic regression analysis: Odds ratio (OR) and 95\% confidence interval (CI) for the association between cognitive impairment and overall consumption of milk and dairy products (categorized by quartiles) in the PREDIMED-PLUS trial. An abnormal MMSE questionnaire was defined as a score $\leq 26$ points. Dependent variable: cognitive decline screening-MMSE score between 27 and 30 points ( 0 ) versus MMSE score $\leq 26$ points (1). Model 1: adjusted for gender, age and BMI. Model 2: additionally adjusted for smoking habit, years of school. Model 3: additionally adjusted for diagnosis of T2D, diagnosis of high blood pressure, diagnosis of depression and moderate to high risk of depression assessed by the BDI-II. Model 4: additionally adjusted for physical activity (measured by total caloric expenditure). Model 5: additionally adjusted for food groups (consumption of meat, fish, vegetables, fruits, dried fruits, alcohol). Model 6: additionally adjusted for exciting foods (coffee, tea, and cocoa). MMSE, Mini-Mental State Examination; $\mathrm{OR}$, odds ratio; $\mathrm{Cl}$ : confidence interval.

33.7\%, respectively (OR 0.689 [0.569-0.834], $p<0.001$ and OR 0.663 [0.547-0.804], $p<0.001$, respectively). This association continued in the adjusted models for Q2 moderate consumption. However, at higher doses this protection was lost due to other variables.

\section{Discussion}

This cross-sectional study showed a significant relationship between the intake of milk and dairy products and the prevalence of cognitive decline measured by the MMSE score. Our results indicated that those subjects that consumed higher milk and dairy product had the poorer cognitive function and an increase in the diagnosis of depression according to the BDI-II. Furthermore, the total consumption of fermented dairy products was also higher in those with worse MMSE scores indicating a higher prevalence of cognitive impairment. By contrast, those individuals who consumed whole-fat milk and dairy products had a lower prevalence of cognitive decline in our middle-aged Spanish population.

Our results regarding cognitive function and milk and dairy product intake are in line with recent studies conducted in other countries. Two prospective cohort studies ${ }^{[16,17]}$ investigating the associations between milk or dairy intake and cognitive 
Table 5. Adjusted models for cognitive decline screening (abnormal MMSE test)—Fermented product intake in quartiles.

Cognitive decline screening (MMSE)

\begin{tabular}{|c|c|c|c|c|c|c|c|}
\hline & \multirow{3}{*}{$\begin{array}{c}\text { Q1 } \\
\text { Fermented } \\
\leq 46 \text { g/day }\end{array}$} & \multicolumn{2}{|l|}{ Q2 } & \multicolumn{2}{|l|}{ Q3 } & \multicolumn{2}{|c|}{ Q4 } \\
\hline & & \multicolumn{2}{|c|}{ Fermented 47-86 g/day } & \multicolumn{2}{|c|}{ Fermented $87-145$ g/day } & \multicolumn{2}{|c|}{ Fermented $\geq 146 \mathrm{~g} /$ day } \\
\hline & & OR (CI) & $p$ & OR (CI) & $p$ & OR (CI) & $p$ \\
\hline Crude model & 1.0 (ref) & $1.167(0.955-1.425)$ & 0.131 & $1.107(0.902-1.359)$ & 0.330 & $1.340(1.106-1.625)$ & 0.003 \\
\hline Model 1 & 1.0 (ref) & $1.157(0.943-1.419)$ & 0.162 & $1006(0.815-1.240)$ & 0.959 & $1.205(0.989-1.468)$ & 0.064 \\
\hline Model 2 & 1.0 (ref) & $1.128(0.909-1.400)$ & 0.275 & $1.016(0.814-1.268)$ & 0.888 & $1.234(1.001-1.521)$ & 0.049 \\
\hline Model 3 & 1.0 (ref) & $1.112(0.893-1.385)$ & 0.344 & $1.016(0.810-1.273)$ & 0.893 & $1.223(0.988-1.513)$ & 0.065 \\
\hline Model 4 & 1.0 (ref) & $1.109(0.890-1.381)$ & 0.358 & $1.006(0.802-1.261)$ & 0.961 & $1.209(0.977-1.497)$ & 0.081 \\
\hline Model 5 & 1.0 (ref) & $1.103(0.885-1.375)$ & 0.384 & $1.000(0.796-1.255)$ & 0.999 & $1.196(0.963-1.484)$ & 0.105 \\
\hline Model 6 & 1.0 (ref) & $1.104(0.886-1.377)$ & 0.379 & $1.004(0.799-1.261)$ & 0.973 & $1.203(0.968-1.494)$ & 0.095 \\
\hline
\end{tabular}

Binary logistic regression analysis: Odds ratio (OR) and $95 \%$ confidence interval (CI) for the association between cognitive impairment associated with fermented dairy product consumption (categorized by quartiles) in the PREDIMED-PLUS trial. An abnormal MMSE questionnaire was defined as a score $\leq 26$ points. Dependent variable: cognitive decline screening-MMSE score between 27 and 30 points (0) versus MMSE score $\leq 26$ points (1). Model 1: adjusted for gender, age and BMI. Model 2: additionally adjusted smoking habit, years of school. Model 3: additionally adjusted for diagnosis of T2D, diagnosis of high blood pressure, diagnosis of depression and moderate to high risk of depression assessed by the BDI-II. Model 4: additionally adjusted for physical activity (measured by total caloric expenditure). Model 5: additionally adjusted for food groups (consumption of meat, fish, vegetables, fruits, dried fruits, alcohol). Model 6: additionally adjusted for exciting foods (coffee, tea, and cocoa). MMSE, Mini-Mental State Examination; OR, odds ratio; $\mathrm{Cl}$ : confidence interval.

Table 6. Adjusted models for cognitive decline screening (abnormal MMSE test)—Whole-fat milk and dairy products consumption (categorized by quartiles) in the PREDIMED-PLUS trial.

Cognitive decline screening (MMSE)

Q1

\begin{tabular}{|c|c|}
\hline Crude model & 1.0 (ref) \\
\hline Model 1 & 1.0 (ref) \\
\hline Model 2 & $1.0(\mathrm{ref})$ \\
\hline Model 3 & 1.0 (ref) \\
\hline Model 4 & 1.0 (ref) \\
\hline Model 5 & 1.0 (ref) \\
\hline Model 6 & 1.0 (ref) \\
\hline
\end{tabular}

Q2

\begin{tabular}{cc}
\hline $\begin{array}{c}\text { Whole-fat milk and dairy products } \\
19-39 \mathrm{~g} / \text { day }\end{array}$ \\
\hline OR (CI) & \multicolumn{1}{c}{$p$} \\
\hline $0.689(0.569-0.834)$ & $<0.001$ \\
$0.725(0.597-0.882)$ & 0.001 \\
$0.756(0.615-0.930)$ & 0.008 \\
$0.748(0.605-0.924)$ & 0.007 \\
$0.756(0.611-0.934)$ & 0.010 \\
$0.752(0.607-0.930)$ & 0.009 \\
$0.754(0.609-0.934)$ & 0.010
\end{tabular}

\begin{tabular}{|c|c|c|c|}
\hline \multicolumn{2}{|c|}{ Q3 } & \multicolumn{2}{|l|}{ Q4 } \\
\hline \multicolumn{2}{|c|}{$\begin{array}{l}\text { Whole fat-milk and dairy products } \\
\qquad 40-102 \mathrm{~g} / \text { day }\end{array}$} & \multicolumn{2}{|c|}{$\begin{array}{l}\text { Whole-fat milk and dairy products } \\
\qquad \geq 103 \mathrm{~g} / \text { day }\end{array}$} \\
\hline $\mathrm{OR}(\mathrm{Cl})$ & $p$ & $\mathrm{OR}(\mathrm{Cl})$ & $p$ \\
\hline $0.663(0.547-0.804)$ & $<0.001$ & $0.751(0.623-0.906)$ & 0.003 \\
\hline $0.739(0.607-0.900)$ & 0.003 & $0.905(0.746-1.098)$ & 0.313 \\
\hline $0.808(0.655-0.997)$ & 0.047 & $0.908(0.738-1.116)$ & 0.358 \\
\hline $0.834(0.674-1.033)$ & 0.096 & $0.916(0.743-1.131)$ & 0.416 \\
\hline 0.841 (0.679-1.042) & 0.112 & $0.929(0.753-1.147)$ & 0.495 \\
\hline $0.838(0.675-1.039)$ & 0.108 & $0.930(0.752-1.150)$ & 0.501 \\
\hline $0.846(0.681-1.051)$ & 0.130 & $0.940(0.759-1.164)$ & 0.570 \\
\hline
\end{tabular}

Binary logistic regression analysis: risk (odds ratio (OR) of cognitive decline associated with whole-fat milk and dairy product consumption categorized by quartiles. An abnormal MMSE questionnaire was defined as a score $\leq 26$ points. Dependent variable: cognitive decline screening-MMSE score between 27 and 30 points $(0)$ versus MMSE score $\leq 26$ points (1). Model 1: adjusted for gender, age and BMI. Model 2: additionally adjusted for smoking habit, years of school. Model 3: additionally adjusted for diagnosis of T2D, diagnosis of high blood pressure, diagnosis of depression and moderate to high risk of depression assessed by the BDI-II. Model 4: additionally adjusted for physical activity (measured by total caloric expenditure). Model 5: additionally adjusted for food groups (consumption of meat, fish, vegetables, fruits, dried fruits, alcohol). Model 6: additionally adjusted for exciting foods (coffee, tea, and cocoa). MMSE, Mini-Mental State Examination; OR, odds ratio; Cl: confidence interval.

functions among older male and female adults after 5 to 20 years of follow-up in France and in the United States showed mixed results. One cohort study assessed milk intake using a FFQ ${ }^{[16]}$ and the other evaluated total dairy and milk intake using a 24-h recall.[17] They utilized different tools to assess cognitive function. The SU.VI.MAX 2 study $^{[16]}$ included a cohort of 3076 participants, 65.5 years of age at the time of neurocognitive evaluation, in which milk consumption was negatively associated with verbal and working memory performance. These results are consistent with results from the ARIC study ${ }^{[17]}$ that suggested that greater milk intake during midlife may be associated with a greater rate of cognitive decline over a 20 -year period.

Previous studies tried to explain the relationship between milk and dairy product constituents or specific ingredients and cognitive health and found contradictory results. ${ }^{[11,13,14,35,36]}$ They were grouped in the first meta-analysis by $\mathrm{Wu}$ et al. ${ }^{[15]}$ which concluded that milk consumption (with or without other dairy products) was significantly associated with a lower risk of cognitive disorders but recognized several limitations due to heterogeneity in the characteristics of the subjects, categories 
and types of milk intake, and different dietary questionnaires and tools to diagnose age-related cognitive disorders.

The role of milk and dairy products in Asian populations deserves further investigation. Consumption patterns in Asian countries differ from those in Western countries, and Asian populations are known to consume less milk and dairy (35). The Hisayama study ${ }^{[36]}$ concluded that milk and fermented dairy products reduce the risk of dementia in the general Japanese population, and the clinical trial by Ogata et al. ${ }^{[37]}$ found that intake of dairy products was highly associated with better short-term memory. However, their results cannot be extrapolated to Caucasian subjects.

The most recent systematic review compiled information from previous studies. Results revealed that the current evidence was inadequate to draw a conclusion for the causal relationship between milk or dairy intake and cognitive decline or disorders in older adults. ${ }^{[20]}$ Our results could be in line with these studies. That systematic review conclusions were made based on included cohort studies that showed large clinical and methodological heterogeneity, hampering the comparability of the study findings, and adjusted for different sets of confounding factors in the statistical analyses.

Our comparison of the consumption of fermented dairy products with the prevalence of cognitive decline showed a higher prevalence of cognitive impairment in those subjects who consumed more fermented dairy products. Several epidemiological and clinical studies have concluded that fermented dairy products can help to less-intense cognitive decline. ${ }^{[35,38]} \mathrm{Cam}$ field et al. ${ }^{[38]}$ suggested, as a possible explanation, that certain bioactive peptides might be beneficial for promoting healthy brain function during ageing. Furthermore, intake of Camembert cheese prevents Alzheimer's disease in a mouse model, ${ }^{[19]}$ and novel lactopeptides from digested fermented dairy products have been investigated. ${ }^{[18]}$ Although these studies suggest that a diet that includes fermented dairy products is beneficial in the prevention of the age-related cognitive decline, their observations were based on peptides whose active compounds responsible for the effect remain to be completely elucidated.

Finally, we found that subjects who consumed whole-fat milk and dairy products had a lower prevalence of cognitive decline according to their MMSE score. Our results are consistent with recent studies that propose certain dairy fatty products may be beneficial for diabetes, metabolic syndrome and cardiovascular diseases. ${ }^{[30,39-42]}$ Interestingly, several recent larger prospective cohort studies including the Nurses' Health Study, ${ }^{[39,40]}$ Health Professionals Follow-Up Study, ${ }^{[40]}$ Multi Ethnic Study of Atherosclerosis ${ }^{[41,42]}$ and the Cardiovascular Health Study ${ }^{[42]}$ have reported substantial beneficial effects of dairy fat products on diabetes prevention. Consequently, the effects of dairy fat and fatty acids found in dairy products on cardiovascular risk need to be further investigated. The findings from our study do not support an adverse association between dairy fat consumption and prevalent cognitive decline. Unexpectedly, low-fat dairy products, but not whole-fat milk and dairy, were found in those participants with greater cognitive decline. The description of dairy intake, including specific dairy products, average intakes, serving sizes, and fat content were widely reported in our study.

In relation to this theory, it has been postulated that phospholipids in the milk fat globule membrane (MFGM) might af- fect cognitive function. ${ }^{[43]}$ There are several possible reasons why the intake of MFGM could benefit cognitive function. ${ }^{[4]}$ First, MFGM contains high levels of choline derivatives (i.e., phosphocholine, glycerophosphocholine, phosphatidylcholine and sphingomyelin). ${ }^{[45]}$ These compounds may play an important role in the development of the nervous system. Second, sphingomyelin metabolites are essential elements of the myelin sheath that covers the axons of neurons. Therefore, sphingomyelin metabolites support the myelination and production of neurotransmitters in the brain. Additionally, previous studies have suggested that dietary phospholipids are effective transporters of essential fatty acids that could improve brain health by lowering endoplasmic reticulum stress ${ }^{[46]}$ which is known to increase the risk of neurodegenerative disorders such as Alzheimer's disease. Lastly, the solubility of phospholipids in brain cell membranes may enhance the neuroplasticity of the hippocampus and support dopamine and glutamate transmission. ${ }^{[45]}$

A cohort study by Almeida et al. found that the regular fullcream milk consumption group demonstrated a significant decrease in successful mental health ageing compared with the rare consumption group (adjusted HR $=0.63[0.45-0.89]] .{ }^{[13]}$ A review by Crichton et al. ${ }^{[47]}$ reported that individuals who consumed lowfat dairy products, including yoghurt and cheese, once a week had a higher cognitive function than those who did not. Subsequently, a survey-based study of self-reported health information undertaken in 2013 found that consumption of low-fat dairy products was associated with increased memory recall, increased social functioning, and decreased stress. ${ }^{[35,36]}$

High dietary intakes of saturated fat have been associated with an increased risk of impaired cognitive function in middle-aged people in elderly populations in both cross-sectional and prospective studies. ${ }^{[48,49]}$ Saturated fat may provide the link between stress and depression, intake of high-fat dairy products, and risk of cognitive decline in the CAIDE study. ${ }^{[50]}$ Nevertheless, these studies were conducted taking into account total dietary fat intake, and no results centered on whole-fat milk and dairy products were analyzed.

Our findings could be related to the modification in the proportion of energy substrates of the diet (fat/carbohydrates) and its possible repercussion at the level of the nervous system. However, these are controversial aspects in the literature, and more research is required in this regard.

\subsection{Methodological Considerations/Limitations}

Given that our study was cross-sectional it was not possible to determine the cause and effect of milk and dairy product consumption on cognitive function. We cannot be sure of the causal direction of these relationships; however, the findings warrant further research exploring milk and dairy products and cognition.

Our study has some considerations that should be taken into account. Self-reported nutritional intake can lead to underestimation or overestimation of true associations, and measurement at only one point may not reflect long-term consumption patterns. Mild cognitive impairment has been shown to attenuate the validity of FFQs when comparing to biomarkers of nutrient intake. ${ }^{[51]}$ Poor cognitive ability was associated with suspected recall errors on the FFQ. These limitations are likely 
to have introduced some misclassification of food intake. We attempted to control for potential confounding variables, adjusted for gender, age, BMI and other related variables.

In light of the limitations in this study, we propose that future research should use biomarkers in order to overcome the limitations of self-reported dietary assessments and standardized assessment tools for cognitive function to identify causal inferences.

As with any health research, often people who are more health conscious are those who are interested in volunteering to participate. In addition, it was not possible to delineate the exact mechanism behind the associations or to exclude a more beneficial lifestyle pattern in whole-fat milk consumers.

Concerning the test administered, the MMSE, the extent of its usefulness has been questioned, especially for milder forms of cognitive impairment. It has also been found that age and education account for $12 \%$ of the variance in MMSE scores. Moreover, we do not know whether milk and dairy intake is associated with established dementia, since patients who had dementia at baseline were excluded from the study. To date, however, the number of studies evaluating cognitive function and milk consumption has been too small to allow a conclusive evaluation of the effect, and thus further investigations are needed.

\section{Concluding Remarks}

We concluded that extensive consumption of milk and dairy products was found in those subjects with worse cognitive function. Higher milk and dairy intake were found in participants with lower MMSE scores. Conversely, whole-fat milk and dairy product intake may play a protective role in cognitive impairment, as higher consumers had better results in MMSE.

Examining the potential biological mechanisms linking dietary consumption and cognitive outcomes in large cohort studies will be critical to understanding the link between milk and dairy intake and multiple outcomes. These results can generate new hypotheses to guide future research. Diet is a modifiable factor that could be considered an appropriate intervention area to optimize cognitive health and well-being throughout life.

\section{Appendix}

\section{List of PREDIMED-Plus study investigators}

Rovira i Virgili University, Department of Biochemistry and Biotechnology, Human Nutrition Unit, University Hospital of Sant Joan de Reus, Pere Virgili Institute for Health Research, Reus, Spain: R. Pedret Llaberia, R. Gonzalez, R. Sagarra Álamo, F. París Palleja, J. Balsells, J. M. Roca, T. Basora Gallisa, J. Vizcaino, P. Llobet Alpizarte, C. Anguera Perpiñá, M. Llauradó Vernet, C. Caballero, M. Garcia Barco, M. D. Morán Martínez, J. García Rosselló, A. Del Pozo, C. Poblet Calaf, P. Arcelin Zabal, X. Floresví, M. Ciutat Benet, A. Palau Galindo, J. J. Cabré Vila, F. Dolz Andrés, M. Soler, M. Gracia Vidal, J. Vilalta J. Boj Casajuana, M. Ricard, F. Saiz, A. Isach, M. Sanchez Marin Martinez, E. Granado Font, C, Lucena Luque, C. Mestres Sola, M. Bulló, N. Babio, N. Becerra-Tomás, G. Mestres, J. Basora, G. Mena-Sánchez, L. Barrubés Piñol, M. Gil Segura, C. Papandreou,
N. Rosique-Esteban, S. Chig, I. Abellán Cano, V. Ruiz García, A. Salas-Huetos, I. Paz-Graniel, L. Sánchez Niembro, P. HernandezAlonso, S. Canudas, L. Camacho-Barcia, J. García-Gavilán, A. Díaz-López.

Department of Preventive Medicine and Public Health, University of Navarra-Navarra Institute for Health Research (IdiSNA), Pamplona, Spain: M. Ruiz-Canela, E. Toledo, P. BuilCosiales, C. Razquin, M. Bes-Rastrollo, A. Sanchez Tainta, B. SanJulian Aranguren, E. Goñi, I. Barrientos, M. Canales, A. Rico, J. Basterra Gortari, A. Garcia Arellano, J. Diez-Espino, O. Lecea-Juarez, J. Carlos Cenoz-Osinaga, J. Bartolome-Resano, A. Sola-Larraza, E. Lozano-Oloriz, B. Cano-Valles, S. Eguaras, E. Pascual Roquet-Jalmar, I. Galilea-Zabalza, H. Lancova, R. Ramallal, M. L. Garcia-Perez, V. Estremera-Urabayen, M. J. Ariz-Arnedo, C. Hijos-Larraz, C. Fernandez Alfaro, B. IñigoMartinez, R. Villanueva Moreno, S. Martin-Almendros, L. Barandiaran-Bengoetxea, C. Fuertes-Goñi, A. Lezaun-Indurain, M. J. Guruchaga-Arcelus, O. Olmedo-Cruz, B. Iñigo-Martínez, L. Escriche-Erviti, R. Ansorena-Ros, R. Sanmatin-Zabaleta, J. Apalategi-Lasa, J. Villanueva-Telleria, M. M. HernándezEspinosa, I. Arroyo-Bergera, L. Herrera-Valdez, L. DorronsoroDorronsoro, Z. Vázquez.

Department of Preventive Medicine, University of Valencia, University Jaume I, Conselleria de Sanitat de la Generalitat Valenciana, Valencia, Spain: J. I. González, J. V. Sorlí, O. Portolés, R. Fernández-Carrión, C. Ortega-Azorín, R. Barragán, E. M. Asensio, O. Coltell, C. Sáiz, R. Osma, E. Férriz, I. GonzálezMonje, F. Giménez-Fernández, L. Quiles, P. Carrasco, N. San Onofre, A. Carratalá-Calvo, C. Valero-Barceló, F. Antón, C. Mir, S. Sánchez-Navarro, J. Navas, I. González-Gallego, L. Bort-Llorca, L. Pérez-Ollero, M. Giner-Valero, R. Monfort-Sáez, J. Nadal-Sayol, V. Pascual-Fuster, M. Martínez-Pérez, C. Riera, M. V. Belda, A. Medina, E. Miralles, M. J. Ramírez-Esplugues, M. Rojo-Furió, G. Mattingley, M. A. Delgado, M. A. Pages, Y. Riofrío, L. Abuomar, N. Blasco-Lafarga, R. Tosca, L. Lizán, A. M. Valcarce, M. D. Medina, R. Monfort, S. de Valcárcel, N. Tormo, O. Felipe-Román, S. Lafuente, E. I. Navío, G. Aldana, J. V. Crespo, J. L. Llosa, L. GonzálezGarcía, R. Raga-Marí.

Cardiovascular Risk and Nutrition Research Group, Endocrinology Service, Neurosciences Programme, Clinical Research Unit at the Hospital del Mar Medical Research Institute (IMIM), Barcelona. Medicine Department, Universitat Autònoma de Barcelona, Barcelona, Spain: M. Fitó, O. Castañer, M. A. Muñoz, M. D. Zomeño, A. Hernaéz, L. Torres, M. Quifer, R. Llimona, G Freixer, K. A. Pérez-Vega, M. Farràs, R. Elosua, J. Vila, I. Subirana, S. Pérez, A. Goday, J. J. Chillaron Jordan, J. A. Flores Lerroux, D. Benaiges Boix, G. Llauradó, M. Farré, E. Menoyo, A. Aldea-Perona, M. Pérez-Otero, D. Muñoz-Aguayo, S. Gaixas, G. Blanchart, A. Sanllorente, M. Soria, J. Valussi, A. Cuenca, L. Forcano, A. Pastor, A. Boronat, S. Tello, M. Cabañero, L. Franco, H. Schröder, R. De la Torre, C. Medrano, J. Bayó, M. T. García, V. Robledo, P. Babi, E. Canals, N. Soldevila, L. Carrés, C. Roca, M.S. Comas, G. Gasulla, X. Herraiz, A. Martínez, E. Vinyoles, J. M. Verdú, M. Masague Aguade, E. Baltasar Massip, M. López Grau, M. Mengual, V. Moldon, M. Vila Vergaz, R. Cabanes Gómez, Ciurana, M. Gili Riu, A. Palomeras Vidal, F Peñas F, A. Raya, M. A. Sebastian, M. Valls, J. Guerrero, M. Marne, E. Minguella, M. Montenegro, A. Sala, M. R. Senan, N. Talens, N. Vera. 
Nutritional Epidemiology Unit, Miguel Hernandez University, ISABIAL-FISABIO, Alicante, Spain: M. Garcia de la Hera, S. González Palacios, L. Torres Collado, D. Valera Gran, L. Compañ Gabucio, L. Notario-Barandiaran, A. Oncina Canovas, D. Orozco Beltran, S. Pertusa Martínez, A. Asensio, Juan Manuel Zazo, C. Gisbert Sellés, J. Román Maciá, C. Sánchez Botella, R. Lloret Macián M. V. Hernándis Marsán, B. Cloquell Rodrigo, M. C. Altozano Rodado, N. Iranzo García, M. C. Martínez Vergara, I. Candela García, R. Valls Enguix, E. P. Cases Pérez, C. M. López García, C. Tercero Maciá, A. Pastor Morell, E. Alonso Bartolomé, J. J. Ballester Baixauli, M. T. Cano Sánchez, B. E. Ayús Rojo, E. Pedro Cases Pérez, C. Tercero Maciá, L. A. Mira Castelló, I. A. García García, M. Jordá Ballesta, C. Pastor Polo, E. Puig Agulló.

Hospital Son Espases (HUSE) and Institute for Health Research Illes Balears (IdISBa), Palma de Mallorca, Spain: M. Fiol, M. Moñino, A. Colom, J. Konieczna, M. Morey, R. Zamanillo, A. M. Galmés-Panadés, V. Pereira, M. A. Martín, A. Yáñez, J. Llobera, J. Ripoll, R. Prieto, F. Grases, A. Costa, C. FernándezPalomeque, E. Fortuny, M. Noris, S. Munuera, F. Tomás, F. Fiol, A. Jover, J. M. Janer, C. Vallespir, I. Mattei, N. Feuerbach, M. del Mar Sureda, S. Vega, L. Quintana, A. Fiol, M. Amador, S. González, J. Coll, A. Moyá, T. Piqué Sistac, M. D. Sanmartín Fernández, M. C. Piña Valls, M. A. Llorente San Martín, J. Pou Bordoy.

Department of Nutrition, Food Sciences, and Physiology, Center for Nutrition Research, University of Navarra, Pamplona, Spain: I. Abete, I. Cantero, C. Cristobo, I. Ibero-Baraibar, M. Zulet, J. Ágreda Martínez, M. D. Lezáun Burgui, N. Goñi Ruiz, R. Bartolomé Resano, E. Cano Cáceres, T. Elcarte López, E. Echarte Osacain, B. Pérez Sanz, I. Blanco Platero, S.A. Andueza Azcárate, A. Gimeno Aznar, E. Ursúa Sesma, B. Ojeda Bilbao, J. Martinez Jarauta, L. Ugalde Sarasa, B. Rípodas Echarte, M. V. Güeto Rubio.

University of Málaga and Institute of Biomedical Research in Malaga (IBIMA), Málaga, Spain: F. J. Barón-López, J. C. Fernández García, N. Pérez-Farinós, N. Moreno-Morales, M. del C. Rodríguez-Martínez, J. Pérez-López, J. C. Benavente-Marín, E. Crespo Oliva, E. Contreras Fernández, F. J. Carmona González, R. Carabaño Moral, S. Torres Moreno, M. V. Martín Ruíz, M. Alcalá Cornide, V. Fuentes Gómez.

Lipids and Atherosclerosis Unit, Department of Internal Medicine, Maimonides Biomedical Research Institute of Cordoba (IMIBIC), Reina Sofia University Hospital, University of Cordoba, Cordoba, Spain: J. López-Miranda, A. Garcia-Rios, J. Criado García, A. I. Jiménez Morales, A. Ortiz Morales, J. D. Torres Peña, F. J. Gómez Delgado, J. F. Alcalá, A. León Acuña, A. P. Arenas Larriva, F. Rodríguez Cantalejo, J. Caballero Villaraso, I. Nieto Eugenio, P. Coronado Carvajal, M. C. del Campo Molina, P. J. Peña Orihuela, I. Perez Corral, G. Quintana Navarro.

Department of Internal Medicine, Institut d'Investigacions Biomèdiques August Pi i Sunyer (IDIBAPS), Hospital Clínic, University of Barcelona, Barcelona, Spain: R. Casas, M. Domenech, C. Viñas, S. Castro-Barquero, A. M. Ruiz-León, R. Losno, L. Tarés, A. Jordán, R. Soriano, M. Camafort, C. Sierra, A. Sala-Vila, J. M. Cots, I. Sarroca, M. García, N. Bermúdez, A. Pérez, I. Duaso, A. de la Arada, R. Hernández, C. Simón, M. A. de la Poza, I. Gil, M. Vila, C. Iglesias, N. Assens, M. Amatller, L. L. Rams, T. Benet, G. Fernández, J. Teruel, A. Azorin, M. Cubells, D. López, J. M. Llovet, M. L. Gómez, P. Climente, L. de Paula, J. Soto, C. Carbonell, C. Llor, X. Abat, A. Cama, M. Fortuny, C.
Domingo, A. I. Liberal, T. Martínez, E. Yañez, M. J. Nieto, A. Pérez, E. Lloret, C. Carrazoni, A. M. Belles, C. Olmos, M. Ramentol, M. J. Capell, R. Casas, I. Giner, A. Muñoz, R. Martín, E. Moron, A. Bonillo, G. Sánchez, C. Calbó, J. Pous, M. Massip, Y. García, M. C. Massagué, R. Ibañez, J. Llaona, T. Vidal, N. Vizcay, E. Segura, C. Galindo, M. Moreno, M. Caubet, J. Altirriba, G. Fluxà, P. Toribio, E. Torrent, J. J. Anton, A. Viaplana, G. Vieytes, N. Duch, A. Pereira, M. A. Moreno, A. Pérez, E. Sant, J. Gené, H. Calvillo, F. Pont, M. Puig, M. Casasayas, A. Garrich, E. Senar, A. Martínez, I. Boix, E. Sequeira, V. Aragunde, S. Riera, M. Salgado, M. Fuentes, E. Martín, A. Ubieto, F. Pallarés, C. Sala, A. Abilla, S. Moreno, E. Mayor, T. Colom, A. Gaspar, A. Gómez, L. Palacios, R. Garrigosa.

Departament of Preventive Medicine and Public Health, University of Granada, Granada, Spain: L. García Molina, B. Riquelme Gallego, N. Cano Ibañez, A. Maldonado Calvo, A. López Maldonado, E. M. Garrido, A. Baena Dominguez, F. García Jiménez, E. Thomas Carazo, A. Jesús Turnes González, F. González Jiménez, F. Padilla Ruiz, J. Machado Santiago, M. D. Martínez Bellón, A. Pueyos Sánchez, L. Arribas Mir, R. Rodríguez Tapioles, F. Dorador Atienza, L. Baena Camus, C. Osorio Martos, D. Rueda Lozano, M. López Alcázar, F. Ramos Díaz, M. Cruz Rosales Sierra, P. Alguacil Cubero, A. López Rodriguez, F. Guerrero García, J. Tormo Molina, F. Ruiz Rodríguez.

OSI ARABA, University Hospital Araba, Vitoria, Spain: I. Salaverria, A. Alonso-Gómez, M. C. Belló, L. Tojal, L. Goicolea, C. Sorto, A. Goikoetxea, A. Casi Casanellas, M. L. Arnal Otero, J. Ortueta Martínez De Arbulo, J. Vinagre Morgado, J. Romeo Ollora, J. Urraca, M. I. Sarriegui Carrera, F. J. Toribio, E. Magán, A. Rodríguez, S. Castro Madrid, M. T. Gómez Merino, M. Rodríguez Jiménez, M. Gutiérrez Jodra, B. López Alonso, J. Iturralde Iriso, C. Pascual Romero, A. Izquierdo De La Guerra.

Research Group on Community Nutrition and Oxidative Stress, University of Balearic Islands, Palma de Mallorca, Spain: M. Abbate, E. Angullo, E. Argelich, M. M. Bibiloni, C. Bouzas, X. Capó, S. Carreres, L. Gallardo, J. M. Gámez, B. García, C. García, A. Julibert, C. Gómez, I. Llompart, A. Martorell, C. M. Mascaró, D. Mateos, M. Monserrat, S. Montemayor, A. Pons, A. Pouso, J. Ramos, V. Ramos, T. Ripoll, T. Rodríguez, L. Sanz, A. Sureda, S. Tejada, L. Ugarriza.

Virgen de la Victoria Hospital, University of Málaga, Málaga, Spain: M. Macías González, J. Ruiz Nava, J. C. Fernández García, A. Muñoz-Garach, A. Vilches Pérez, A. González Banderas, A. V. Alarcón-Martín, M. García Ruiz de Mier, J. Alcaide Torres, A. Vargas Candela, M. León Fernández, R. Hernández Robles, S. Santamaría Fernández, J. M. Marín.

University of Las Palmas de Gran Canaria, Las Palmas, Spain: J. Álvarez-Pérez, E. M. Díaz Benítez, F. Díaz-Collado, A. SánchezVillegas, J. Pérez-Cabrera, L. T. Casañas-Quintana, R. B. GarcíaGuerra, I. Bautista-Castaño, C. Ruano-Rodríguez, F. Sarmiento de la Fe, J. A. García-Pastor, B. Macías-Gutiérrez, I. FalcónSanabria, C. Simón-García, A. J. Santana-Santana, J. B. ÁlvarezÁlvarez, B. V. Díaz-González, J. M. Castillo Anzalas, R. E. SosaAlso, J. Medina-Ponce.

Biomedicine Institute (IBIOMED); University of León, and Primary Health Care Management of León (Sacyl), León, Spain: S. Abajo Olea, A. Adlbi Sibai, A. Aguado Arconada, L. Álvarez, E. Carriedo Ule, M. Escobar Fernández, J. I. Ferradal García, J. P. Fernández Vázquez, M. García González, C. González 
Donquiles, C. González Quintana, F. González Rivero, M. Lavinia Popescu, J. I. López Gil, J. López de la Iglesia, A. Marcos Delgado, C. Merino Acevedo, S. Reguero Celada, M. Rodríguez Bul, L. Vilorio-Marqués.

Department of Family Medicine, Distrito Sanitario Atención Primaria Sevilla, Sevilla, Spain: J. M. Santos-Lozano, C. Domínguez-Espinaco, S. Vaquero-Díaz, F. J. García-Corte, A. Santos-Calonge, C. Toro-Cortés, N. Pelegrina-López, V. Urbano-Fernández, M. Ortega-Calvo, J. Lozano-Rodríguez, I. Rivera-Benítez, M. Caballero-Valderrama, P. Iglesias-Bonilla, P. Román-Torres, Y. Corchado-Albalat, L. Mellado-Martín.

Department of Endocrinology and Nutrition, Hospital Fundación Jimenez Díaz. Instituto de Investigaciones Biomédicas IISFJD. University Autonoma, Madrid, Spain: A. I. de Cos, C Vázquez, S.Más-Fontao, S Gutierrez, A. Galdon, E Martínez, C. Calderon, R. Sierra, B. Luca, C. Cruces, E. Civantos, M. J. Silva, S. Artola, J. S. Chacin.

Lipids and Vascular Risk Unit, Internal Medicine, University Hospital of Bellvitge-IDIBELL, Hospitalet de Llobregat, Barcelona, Spain: X. Pintó, A. Galera, M. Gimenez-Gracia, E. de la Cruz, R. Figueras, M. Poch, R. Freixedas, F. Trias, I. Sarasa, M. Fanlo-Maresma, H. Lafuente, M. Liceran, A. Rodriguez-Sanchez, C. Pallarols, E. Gómez-Sanchez, V. Esteve-Luque, J. Monedero, X. Corbella, E. Corbella.

Department of Endocrinology, IDIBAPS, Hospital Clinic, University of Barcelona, Barcelona, Spain: A. Altés, I. Vinagre, C. Mestre, J. Viaplana, M. Serra, J. Vera, T. Freitas, E. Ortega, I. Pla, R. Olbeyra.

Nutritional Genomics and Epigenomics Group, Institute IMDEA-Food, CEI UAM+CSIC, Madrid, Spain: J. M. Ordovás, V. Micó, L. Berninches, M. J. Concejo, J. Muñoz, M. Adrián, Y. de la Fuente, C. Albertos, E. Villahoz, M. L. Cornejo, C. Cuesta, A. Montero, M. C. Valdés.

Division of Preventive Medicine, University of Jaén, Jaén, Spain: J. J. Gaforio, S. Moraleda, N. Liétor, J. I. Peis, T. Ureña, M. Rueda, M. I. Ballesta.

Department of Endocrinology and Nutrition, Instituto de Investigación Sanitaria Hospital Clínico San Carlos (IdISSC), Madrid, Spain: C. Moreno Lopera, C. Aragoneses Isabel, M. A. Sirur Flores, M. Ceballos de Diego, T. Bescos Cáceres, Y. Peña Cereceda, M. Martínez Abad, R. Cabrera Vélez, M. González Cerrajero, M. A. Rubio Herrera, M. Torrego Ellacuría, A. Barabash Bustelo, M. Ortiz Ramos, A. Larrad Sainz.

Oxidative Pathology Unit, Department of Biochemistry and Molecular Biology, School of Medicine-INCLIVA, Service of Clinical Analyses, University Hospital Doctor Peset, Valencia, Spain. University of Valencia, Valencia Spain: G. Sáez Tormo (Sáez GT), N. Estañ-Capell, A. Iradi Casal, L. Monzó Beltrán, C. Bañuls Morant, E. Alonso Iglesias, D. Acevedo León, A. Hernando Espinilla, A. Mora Herranz, S. Alcover Sáez, J. Murado Pardo, J. Ventura Gayete, M. L. Santaolaria Ayora, A. Carbonell Moncho.

Department of Preventive Medicine, University of Malaga, Malaga, Spain: J. Fernández-Crehuet Navajas, M. Gutiérrez Bedmar, A. García Rodriguez, A. Mariscal Larrubia, M. Carnero Varo, C. Muñoz Bravo.

Department of Psychiatry, University Hospital of Bellvitge, Barcelona, Spain: F. Fernández-Aranda, S. Jiménez-Murcia, N. Mallorqui-Bagué, R. Granero, Z. Agüera, M. Lozano-Madrid.

\section{Supporting Information}

Supporting Information is available from the Wiley Online Library or from the author.

\section{Acknowledgements}

The authors acknowledge M. Repice for English language editing of this article. This work was supported in part by grants from Instituto de Salud Carlos III (PI13/00673, PI13/00492, PI13/00272, PI13/01123, PI13/00462, $\mathrm{PI} 13 / 00233, \mathrm{PI} 13 / 02184, \mathrm{PI} 3 / 00728, \mathrm{PI} 13 / 01090, \mathrm{PI} 13 / 01056, \mathrm{PI} 14 /$ 01722, PI14/00636, PI14/00618, PI14/00696, PI14/01206, PI14/01919, $\mathrm{PI} 14 / 00853, \mathrm{PI} 14 / 01374, \mathrm{PI} 16 / 00473, \mathrm{PI} 16 / 00662, \mathrm{PI} 16 / 01873, \mathrm{PI} 16 /$ 01094, PI16/00501, PI16/00533, PI16/00381, PI16/00366, PI16/01522, $\mathrm{PI} 16 / 01120, \mathrm{PI} 17 / 00764, \mathrm{PI} 17 / 01183, \mathrm{PI} 17 / 00855, \mathrm{PI} 17 / 01347, \mathrm{PI} 17$ / 00525, PI17/01827, PI17/00532, PI17/00215, PI17/01441, PI17/00508, PI17/01732, and PI17/00926); the Cohorte PREDIMED-PLUS grant; the European Research Council (Advanced Research Grant 2013-2018, 340918); the Recercaixa grant (2013ACUP00194); grants from Consejeria de Salud de la Junta de Andalucia (PI0458/2013, PS0358/2016, PI0092/2017, PI0096/2017 and PI0137/2018); a grant from the Generalitat Valenciana (PROMETEO/2017/017); a SEMERGEN grant, and funds from the European Regional Development Fund (CB06/03). This study has been co-funded by FEDER funds. A.M-G. is the recipient of a postdoctoral grant (Juan Rodes JR 17/00023) from the Spanish Ministry of Economy and Competitiveness. I.C.-P. was supported by Rio Hortega (CM 17/00169) and now is the recipient of a postdoctoral grant (Juan Rodes JR 19/00054) from the Spanish Ministry of Economy and Competitiveness. J.C.F.-G. was supported by a research contract from the Servicio Andaluz de Salud (SAS) (B-0003-2017). I.P.G. has received a grant from the Spanish Ministry of Education, Culture and Sports (FPU 17/01925). M.R.B.-L. was supported by "Miguel Servet Type I" program (CP15/00028) from the ISCIII-Madrid (Spain), cofinanced by the Fondo Europeo de Desarrollo Regional-FEDER.

\section{Conflict of Interest}

The authors declare no conflict of interest.

\section{Author Contributions}

A.M.-G. and I.C.-P. contributed equally to this work and share the first authorship. A.M.-G. and F.J.T. designed the research; A.M.-G., I.C.P., and F.J.T. wrote the manuscript; A.M.-G., J.C.F.-G., and M.R.B.-L. conducted research; J.C.F.-G. and I.C.-P. analyzed data; A.M.-G. and I. C-P. had the primary responsibility for the final content.

\section{Data Availability Statement}

The data that support the findings of this study are available on request from the corresponding author. The data are not publicly available due to privacy or ethical restrictions.

\section{Keywords}

cognition, cognitive decline, consumption, dairy products, milk

Received: July 23, 2020

Revised: December 30, 2020

Published online: March 5, 2021 
[1] M. Wortmann, Alzheimers Res. Ther. 2012, 4, 40.

[2] C. P. Ferri, M. Prince, C. Brayne, H. Brodaty, L. Fratiglioni, M. Ganguli, K. Hall, K. Hasegawa, H. Hendrie, Y. Huang, A. Jorm, C. Mathers, P. R. Menezes, E. Rimmer, M. Scazufca, Lancet 2005, 366, 2112.

[3] United Nations, World Population Ageing 1950-2050, United Nations, New York 2001

[4] R. C. Petersen, G. E. Smith, S. C. Waring, R. J. Ivnik, E. G. Tangalos, E. Kokmen, Arch. Neurol. 1999, 56, 303.

[5] J. Bryan, Ageing Int. 2004, 29, 28.

[6] V. Solfrizzi, F. Panza, A. Capurso, J. Neural Transm. 2003, 110, 95.

[7] Y. Gu, J. W. Nieves, Y. Stern, J. A. Luchsinger, N. Scarmeas, Arch. Neurol. 2010, 67, 699

[8] P. P. Zandi, J. C. Anthony, A. S. Khachaturian, Arch. Neurol. 2004, 61, 82

[9] T. Cederholm, N. Salem, Jr., J. Palmblad, Adv. Nutr. 2013, 4, 672.

[10] L. Lee, S. A. Kang, L. HO, Public Health 2001, 115, 133.

[11] A. Rahman, P. Sawyer Baker, R. M. Allman, J. Nutr. Health Aging 2007, 11, 49.

[12] K. M. Park, V. L. Fulgoni, III, Br. J. Nutr. 2013, 109, 1135.

[13] O. P. Almeida, P. Norman, G. Hankey, K. Jamrozik, L. Flicker, Am. J. Geriatr. Psychiatry 2006, 14, 27.

[14] M.-N. Vercambre, M.-C. Boutron-Ruault, K. Ritchie, F. ClavelChapelon, C. Berr, Br. J. Nutr. 2009, 102, 419.

[15] L. Wu, D. Sun, Nutrients 2016, 8, 824.

[16] E. Kesse-Guyot, K. E. Assmann, V. A. Andreeva, M. Ferry, S. Hercberg, P. Galan, J. Nutr. Health Aging 2016, 20, 128.

[17] N. Petruski-Ivleva, A. Kucharska-Newton, P. Palta, D. Couper, K. Meyer, M. Graff, B. Haring, R. Sharrett, G. Heiss, Nutrients 2017, 9, 1134.

[18] Y. Ano, T. Ayabe, T. Kutsukake, R. Ohya, Y. Takaichi, S. Uchida, K. Yamada, K. Uchida, A. Takashima, H. Nakayama, Neurobiol. Aging 2018, 72,23

[19] Y. Ano, M. Ozawa, T. Kutsukake, S. Sugiyama, K. Uchida, A. Yoshida, H. Nakayama, PLoS One 2015b, 11, e0118512.

[20] J. Lee, Z. Fu, M. Chung, D. J. Jang, H. J. Lee, Nutr. J. 2018, 17, 82.

[21] Z. Arvanitakis, R. S. Wilson, J. L. Bienias, D. A. Evans, D. A. Bennett, Arch. Neurol. 2004, 61, 661

[22] R. O. Roberts, D. S. Knopman, Y. E. Geda, Alzheimers Dement. 2014, 10, 18.

[23] D. E. Barnes, K. Yaffe, Lancet Neurol. 2011, 10, 819.

[24] M. B. Zemel, J. Am. Coll. Nutr. 2005, 24, 537 S.

[25] L. M. Steffen, C. H. Kroenke, X. Yu, M. A. Pereira, M. L. Slattery, L. Van Horn, M. D. Gross, D. R. Jacobs, Jr., Am. J. Clin. Nutr. 2005, 82, 1169.

[26] L. Wang, J. E. Manson, J. E. Buring, I. M. Lee, H. D. Sesso, Hypertension 2008, 51, 1073.

[27] H. K. Choi, W. C. Willett, M. J. Stampfer, E. Rimm, F. B. Hu, Arch Intern. Med. 2005, 165, 997.

[28] S. Liu, H. K. Choi, E. Ford, Y. Song, A. Klevak, J. E. Buring, J. E. Manson, Diabetes Care 2006, 29, 1579.

[29] M. A. Martínez-González, P. Buil-Cosiales, D. Corella, M. Bulló, M. Fitó, J. Vioque, D. Romaguera, J. A. Martínez, J. Wärnberg, J. LópezMiranda, R. Estruch, A. Bueno-Cavanillas, F. Arós, J. A. Tur, F. Tina- hones, L. Serra-Majem, V. Martín, J. Lapetra, C. Vázquez, X. Pintó, J. Vidal, L. Daimiel, M. Delgado-Rodríguez, P. Matía, E. Ros, F. Fernández-Aranda, C. Botella, M. P. Portillo, R. M. Lamuela-Raventós, A. Marcos, G. Sáez, E. Gómez-Gracia, M. Ruiz-Canela, E. Toledo, I. Alvarez-Alvarez, J. Díez-Espino, J. V. Sorlí, J. Basora, O. Castañer, H. Schröder, E. M. Navarrete-Muñoz, M. A. Zulet, A. García-Rios, J. Salas-Salvadó, PREDIMED-Plus Investigators, Int. J. Epidemiol. 2019, $48,387$.

[30] K. G. Alberti, R. H. Eckel, S. M. Grundy, P. Z. Zimmet, J. I. Cleeman, K. A. Donato, Circulation 2009, 120, 1640.

[31] J. Peña-Casanova, R. Blesa, M. Aguilar, N. Gramunt-Fombuena, B. Gómez-Ansón, R. Oliva, Arch. Clin. Neuropsychol. 2009, 24, 307.

[32] American Psychiatric Association, Diagnostic and Statistical Manual of Mental Disorders (DSM-IV), American Psychiatric Association, Washington, DC 1994.

[33] M. F. Folstein, S. E. Folstein, P. R. McHugh, J. Psychiatr. Res. 1975, 12, 189.

[34] A. T. Beck, R. A. Steer, G. K. Brown, BDI-II Beck Depression Inventory Manual, 2nd ed. Psychological Corporation, San Antonio, TX 1996.

[35] M. Ozawa, T. Ninomiya, T. Ohara, Y. Doi, K. Uchida, T. Shirota, K. Yonemoto, T. Kitazono, Y. Kiyohara, Am. J. Clin. Nutr. 2013, 97, $1076 \mathrm{e} 1082$

[36] M. Ozawa, T. Ohara, T. Ninomiya, J. Hata, D. Yoshida, N. Mukai, M. Nagata, K. Uchida, T. Shirota, T. Kitazono, Y. Kiyohara, J. Am. Geriatr. Soc. 2014, 62, 1224e 1230

[37] S. Ogata, H. Tanaka, K. Omura, C. Honda, K. Hayakawa, Clin. Nutr. 2016, 35, 507e513.

[38] D. A. Camfield, L. Owen, A. B. Scholey, A. Pipingas, C. Stough, Br. J. Nutr. 2011, 106, 159e174.

[39] M. Y. Yakoob, P. Shi, F. B. Hu, H. Campos, K. M. Rexrode, E. J. Orav, W. C. Willett, D. Mozaffarian, Am. J. Clin. Nutr. 2014, 100, 1437.

[40] M. Y. Yakoob, P. Shi, W. C. Willett, K. M. Rexrode, H. Campos, E. J. Orav, F. B. Hu, D. Mozaffarian, Circulation 2016, 133, 1645.

[41] D. Mozaffarian, H. Cao, I. B. King, R. N. Lemaitre, X. Song, D. S. Siscovick, G. S. Hotamisligil, Ann. Intern. Med. 2010, 153, 790.

[42] D. Mozaffarian, M. C. de Oliveira Otto, R. N. Lemaitre, A. M. Fretts, G. Hotamisligil, M. Y. Tsai, D. S. Siscovick, J. A. Nettleton, Am. J. Clin. Nutr. 2013, 97, 854

[43] J. M. Hess, S. S. Jonnalagadda, J. L. Slavin, Compr. Rev. Food Sci. Food Saf. 2016, 15, 251

[44] V. Spitsberg, J. Dairy Sci. 2005, 88, 2289.

[45] V. Verardo, A. M. Gómez-Caravaca, D. Arráez-Román, K. Hettinga, Int. J. Mol. Sci. 2017, 18, 173.

[46] V. Conway, S. F. Gauthier, Y. Pouliot, Anim. Front. 2014, 4, 44

[47] G. E. Crichton, J. Bryan, K. J. Murphy, J. Buckley, Dement. Geriatr. Cognit. Disord. 2010, 30, 352e361.

[48] M. C. Morris, D. A. Evans, J. L. Bienias, C. C. Tangney, R. S. Wilson, Neurology 2004, 62, 1573.

[49] S. Kalmijn, M. P. van Boxtel, M. Ocke, W. M. Verschuren, D. Kromhout, L. J. Launer, Neurology 2004, 62, 275.

[50] M. H. Eskelinen, T. Ngandu, E. L. Helkala, J. Tuomilehto, A. Nissinen, H. Soininen, M. Kivipelto, Int. J. Geriatr. Psychiatry 2008, 23, 741.

[51] K. Zuniga, E. McAuley, J. Nutr. Health Aging 2015, 19, 333. 